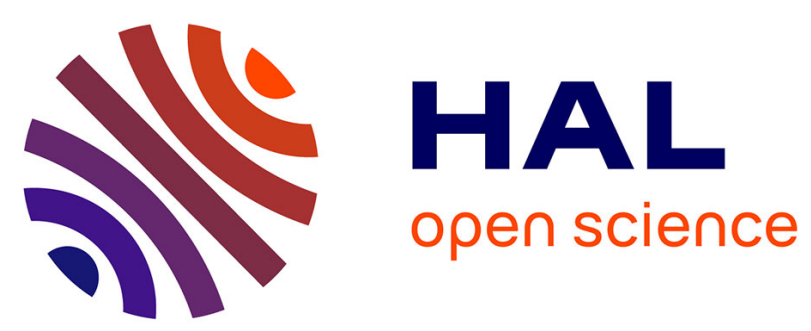

\title{
A Shared Framework of Reference, a First Step Toward Engineers' and Biologists' Synergic Reasoning in Biomimetic Design Teams
}

Eliot Graeff, Nicolas Maranzana, Améziane Aoussat

\section{- To cite this version:}

Eliot Graeff, Nicolas Maranzana, Améziane Aoussat. A Shared Framework of Reference, a First Step Toward Engineers' and Biologists' Synergic Reasoning in Biomimetic Design Teams. Journal of Mechanical Design, 2021, 143 (4), pp.1-14. 10.1115/1.4047905 . hal-03016438

\author{
HAL Id: hal-03016438 \\ https://hal.science/hal-03016438
}

Submitted on 20 Nov 2020

HAL is a multi-disciplinary open access archive for the deposit and dissemination of scientific research documents, whether they are published or not. The documents may come from teaching and research institutions in France or abroad, or from public or private research centers.
L'archive ouverte pluridisciplinaire HAL, est destinée au dépôt et à la diffusion de documents scientifiques de niveau recherche, publiés ou non, émanant des établissements d'enseignement et de recherche français ou étrangers, des laboratoires publics ou privés. 


\author{
Eliot Graeff \\ Arts et Metiers Institute of Technology, LCPI, \\ HESAM Université, \\ F-75013 Paris, France \\ e-mail: eliot.graeff@ensam.eu \\ Nicolas Maranzana \\ Arts et Metiers Institute of Technology, LCPI, \\ HESAM Université, \\ F-75013 Paris, France \\ e-mail: nicolas.maranzana@ensam.eu \\ Améziane Aoussat \\ Arts et Metiers Institute of Technology, LCPI, \\ HESAM Université, \\ F-75013 Paris, France \\ e-mail: Ameziane.Aoussat@ensam.eu
}

\section{A Shared Framework of Reference, a First Step Toward Engineers' and Biologists' Synergic Reasoning in Biomimetic Design Teams}

Biomimetic practice requires a diverse set of knowledge from both biology and engineering. Several researchers have been supporting the integration of biologists within biomimetic design teams in order to meet those biological requirements and improve the effectiveness of biomimetic processes. However, interdisciplinarity practices create well-known communication challenges. Based on functional representations (like SAPPhIRE or function behavior structure (FBS)), several approaches to model biological information have been investigated in the literature. Nonetheless, actual communication processes within interdisciplinary biomimetic design teams are yet to be studied. Following this research axis, this publication focuses on communication noises and wonders if a shared framework of reference can be defined to improve communication between biologists and engineers? Through the comparison of processes and graphic representations between biology and engineering design, a set of guidelines is defined to structure a shared framework of reference. Within this framework, a new tool referred to as LINKAGE is then proposed to assist interdisciplinary communication during the biomimetic process. [DOI: 10.1115/1.4047905]

Keywords: cognitive-based design, collaborative design, conceptual design, design teams, multidisciplinary design and optimization

\section{Introduction}

From Leonardo Da Vinci, to Otto Schmitt, to Benyus [1], bio-inspiration, or looking at living organisms for inspiration, has been an approach of increasing interest in the scientific community. Biomimetics, as the technical prism focusing on bio-inspiration, is a crucial element in the spread and implementation of these new practices. Biomimetics is defined as "the interdisciplinary cooperation of biology and technology or other fields of innovation with the goal of solving practical problems through the function analysis of biological systems, their abstraction into models and the transfer into and application of these models to the solution" [2].

If the potential of biomimetics has been proven over the past decades $[3,4]$, it struggles to become an innovation strategy of reference. Scientific literature underlines interdisciplinary communication as one of biomimetics' main challenges [5-9]. Following a literature review on biomimetics and communication theories, a set of impediments to communication are identified and analyzed in the context of interdisciplinary biomimetic design teams.

This paper then investigates communication challenges between biologists and engineers and wonders if a common framework of reference can be defined to support communication between biologists and engineers in interdisciplinary biomimetic design teams?

To answer the research question, we compared engineering design and biology regarding processes and representations. The results of this comparative analysis are formalized as guidelines building a shared framework of reference. Within this framework, a tool referred to as LINKAGE is created and its structure and characteristics are presented. Relying on the abovementioned

Contributed by the Design Theory and Methodology Committee of ASME for publication in the Journal of Mechanical Design. Manuscript received January 24 2020; final manuscript received June 23, 2020; published online October 12, 2020. Assoc. Editor: Daniel A. McAdams. guidelines, LINKAGE aims at guiding the biomimetic practice while assisting interdisciplinary communication.

This study is made up of two phases. First, the theoretical part leads to the formalization of the common framework of reference and the design of LINKAGE. Second, the practical part presents the tool's development in the form of an open-access website along with its evaluation through assessments by experts and workshops with professionals. Where this publication describes the theoretical part, it does not address the practical part.

\section{State of the Art}

This section presents the current methodological approaches surrounding biomimetics and focuses on communication issues. For information on the historical development and legitimacy of the biomimetic design approach, we refer the reader to thorough reviews of the literature $[10,11]$.

2.1 Biomimetic Methodologies. Biomimetic processes are of two types. Either the design phase occurs after a biological discovery, which leads to a new product often with a high added value: the biology push approach [2], or biomimetics operates as a problem-solving process: the technology pull approach [2]. The latter is the core of engineering design processes in industry. Thus, numerous research projects have been investigating its methodological framework.

The literature describes more than 15 processes allowing the implementation of a technology pull approach [12], the procedural model of doing bionics [13], the biomimetic design methodology [14], the problem-driven analogical process [15], the BID process [16], etc. Overall, according to Fayemi, biomimetic processes can be described with eight main steps synthesized into a unified technology pull biomimetic process [12]. A recent study optimized the 


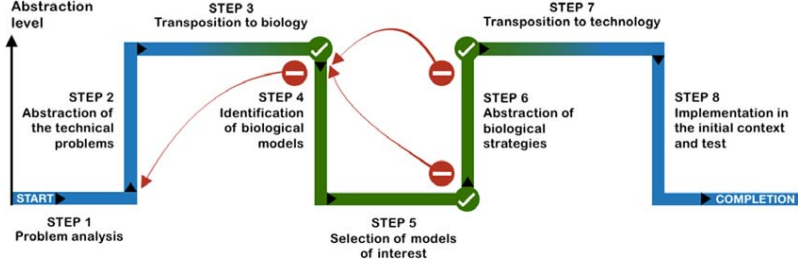

Fig. 1 Unified technology pull biomimetics process optimized for risk management

unified technology pull process for interdisciplinary teams and risk management (Fig. 1) [17].

To perform these different steps, practitioners rely on tools. According to Wanieck et al. [8], these tools can be specific to a biomimetic process, and as a result were designed for biomimetic purposes only, like BioTRIZ [18], or they can be adapted from engineering, such as 5-Whys [19], or biology, for instance, 16 patterns of nature [20].

We must specify that the tools that are said to come from biology are neither biological tools nor tools designed to be used by biologists. They have been mainly designed for engineers to learn about biological findings.

Despite those methodological contributions, biomimetics fails to spread and to reach its full potential.

2.2 Methodological Limitations. Vattam and Goel [21] and Kruiper et al. [22] summarized three main issues designers currently face during biomimetic projects:

- Findability, that we may interpret as how can design teams find suitable biological data for each, or at least most, of their design projects?

- Recognizability, that we may interpret as how can design teams identify, among the incredible diversity of living beings, which organisms are relevant for a given design problem?

- Understandability, that we may interpret as how to overcome the lack of biological knowledge of design teams during the steps involving biology (step 3 to 7 of the unified process)?

Consequently, the gap between the engineering and biological fields (knowledge, reasoning, data structure, etc.) is one of the main issues. In previous work, we drew a distinction between two types of biologists. "Vertical biologists" to refer to biologists who punctually interact with design team and have an in-depth expertise in a specific field (i.e., a vertical knowledge) identified as researchers, and "Horizontal biologist" to refer to integrated teammate having a broad training in biology (i.e., a horizontal knowledge) associated with a cross-domain thinking [17,23].

Numerous processes suggest interacting with vertical biologists $[13,16,22,24,25]$ but only a few prescriptive processes, in the sense of Wynn and Clarkson [26] and Gericke and Blessing [27], describe the practice of an interdisciplinary team composed of biologists and engineers [28,29]. As stated by McCardle et al., "Promote best practices for interdisciplinary working, ensuring biologists, life science specialists and experts are effectively involved with design teams and technologists. This is a major part of biomimicry practice and training but is not a standard approach with many industries or universities" [7].

A fundamental contradiction thus emerges. Facing these challenges, the need to further integrate biologists is underlined in the literature [30,31], but the methodological framework (process and tools), has not been originally designed to include these unusual profiles. In other words, methodological research on engineering design have been focusing on the process-centered aspects (the "how?") but have not been much investigating the professioncentered aspects yet (the "who?").

In addition to the inadequacy between process-centered and profession-centered framework, interdisciplinary teamwork itself is challenging. As presented in Sec. 1, poor communication between actors having different backgrounds appears as one on the main obstacles. Helms et al. explain these obstacles as follows "biologists and engineers typically speak a very different language, creating communication challenges," "they typically use different methods of investigation and often have different perspectives on design" [32]. Fayemi also identifies three explanations "Their different backgrounds lead to divergent disciplinary or functional understanding of a concept, whether due to perception, languages, or 'thought styles'." [12].

To guide our reasoning, Sec. 2.3 presents the foundations of communication theories.

\subsection{Communication Theories as a Prism to Consider} Biomimetic Teams' Issues

2.3.1 Origins and Related Concepts. Also known as the information theory, the first theory of communication was proposed by Shannon in 1948 [33]. This theory describes several fundamental concepts surrounding communication to quantify a coded information through statistical analysis. According to this theoretical cornerstone, communication systems comprise five elements:

- An information source, which is the origin of a message or group of messages to be transmitted. These messages represent the information of interest as understood by the source.

- A transmitter, which converts the message into a signal (encoding) suitable for a given channel of transmission.

- A channel, the medium which transmits the signal.

- A receiver, which interprets the signal to reconstruct the message (decoding).

- A destination, the entity to whom the message is intended.

A sixth transversal element, the "noise source," modifies the signal at its emission, during its transmission or at its reception, altering the encoded message. Shannon's theory presents communication with a technical standpoint which leads to a model that cannot be generalized to all the system, people debating for example. Following this seminal theory, several researchers published additional contributions and optimizations.

In particular, Berlo extends the model to the communication between two people [34], Schramm integrates feedback along with the crucial role of context [35], and Devito characterizes four types of noise: physical noise, physiological noise, psychological noise, and semantic noise [36].

Altogether, these studies constitute a representative part of the conceptual foundations on communication.

2.3.2 Communication Theory Applied to a Biomimetic Team. Applied to interdisciplinary design teams, these theories can be used to question the emergence of communication issues. Figure 2 presents a communication model applied to an engineer (source/receiver) and a horizontal biologist (source/receiver) talking (channel/signal) about a biological solution (message/ feedback).

According to the communication theories, a lot of interrelated factors can prevent a good communication: noises caused by a lack of common context (commonness, social and cultural framework of reference, etc.), source/receiver's defaults (poor communication skills, attitudes, knowledge, etc.), a badly encoded/decoded message (wrong code, ill-structured), etc.

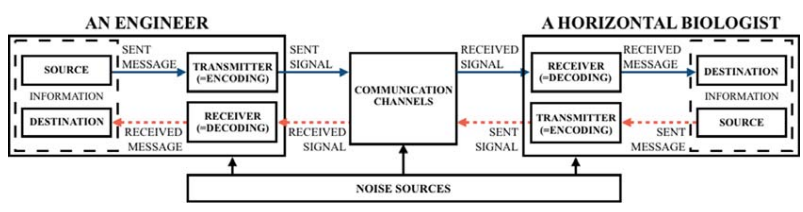

Fig. 2 Communication theory applied to a biomimetic design team (based on Shannon model and communication theories) 
The different backgrounds of the actors can be associated with several of these issues. First, because of the distance between biologists' and an engineers' habits, know-hows and knowledges, their point of view, and cognitive reasoning vary. This diversity induces a lack of common cognitive reasoning, also called "cognitive dissonances." For example, engineers are trained to design solution through a prescriptive approach and biologists are trained to breakdown and describe phenomena through a descriptive approach, ultimately leading to different considerations when dealing with a problem as described by Bogatyrev and Bogatyreva [37].

Moreover, semantic noises are likely to occur. The most obvious example here is the linguistic gap between engineers and biologists. Depending on the source's and receiver's backgrounds, a word might also carry several pieces of information. If a biologist talks about "photosynthesis," the concept associated with this word is probably much more complex than what might be understood by an engineer. The biologist then assumes the engineer's degree of knowledge on associated concepts, which can lead to loss of information.

Furthermore, since the background impacts the process of encoding, the types of signal can significantly vary. Among other signals, engineers transmit information in the form of requirements specifications, equations, technical schematics, etc. These forms of encoding might be unknown by biologists and so not easily decoded. The receiver will detect a signal but will wonder how to deal with it.

Finally, team members may reason on different frameworks of reference regarding the project's objectives. If they do not share the same mental model of constraints, expectations and goals, the overall project is likely to fail [38].

As our study focuses on the methodological aspects, the source/ receiver's defaults, like researchers' bad communication skills, are not addressed.

To summarize, interdisciplinary teams need guidance on semantic and psychological noises to allow actors to keep their specificities while communicating efficiently.

2.4 Lack of Communication, a Challenge for Biologists' Integration. The inability to communicate efficiently is as a wellknown issue in interdisciplinary teams [39] and the integration of biologists in biomimetic teams is not exception to the rule.

As presented in Sec. 2.3.2, linguistic differences (semantic noise) leading to vocabulary shortcomings or misunderstanding are widely recognized and easily understandable issues. In the biomimetic literature, various publications deal with semantic divergences through a data-centered prism.

A first set of studies focuses on semantic issues during the search for biological information by engineers. To support this search phase, Cheong et al. identified biological meaningful keywords and associated them with engineering concepts through computational tools leading to search algorithms [40]. On the same axis, Nagel et al. established an engineering-to-biology thesaurus which aims at "providing a list of synonymous biological terms to the generalized engineering terms of the Functional Basis modeling lexicon." Applications are oriented toward both the search and the analysis of biological data "without having an extensive background in biological knowledge" [41]. Where this tool has been evaluated by an expert in biology, it is designed to assist engineers during their manipulation of biological data. Likewise, the Biomimicry Institute published the Biomimicry Taxonomy [28], a tool co-designed with biologists to help engineers formulate biological requests from functional concepts. The aim of this tool is to support the search for biological data in the AskNature database [42].

Finally, at a more abstract level, Vincent studied the formalization of networks of concepts in an ontology [43] with the aim of building a computational tool supporting searches based on tradeoffs [44].

According to the concepts presented in Sec. 2.3, these contributions deal with the format of signal (suitable for biology or technology) and its encoding/decoding. The final goal is to improve the effectiveness of engineers' (destination) search in databases or ontology (structured sources) or on the web (nonstructured source).

Another part of the literature studies the representation of biological systems through causal models. The aims of these approaches are to enhance understandability through modeling, improve findability by linking biological models with technical models and to generate databases of structured biological information. The first type of representation is functional model. These models can be preexisting and adapted for biomimetics purposes, such as the function behavior structure (FBS) model for the DANE database [45], or format specifically designed for biomimetic, like the State change, Action, Parts, Phenomenon, Input, oRgan, Effect (SAPPhIRE) model for IDEA-INSPIRE [46]. Both constructs aim at identifying causalities between elements to explain functional properties. The second type of model is flow-based functional model. Nagel et al. designed such model, presenting the flows of energy, matter, and signal between generic functional sub-systems based on the previously presented thesaurus (e.g., Export, Store, etc.) [24]. Models are then stored in the Design Repository. In the case study presenting the approach, Nagel indicates that the model was discussed with an expert in biology but the contribution of the model on communication itself is not analyzed. The last model, BABELE, proposed by Fayemi et al. [23] aims at combining the theoretical approach of biology, in particular the concept of autopoiesis [47], systemics, through the Miller's Living System Theory [48] and engineering, using TRIZ [49]. The model "tries hard to allow people, without any specific biological knowledge, to arrange by relevancy the identified biological systems on their own." As specified by Fayemi, it is a tool made for "designers with limited biological knowledge" and to delay biologists' intervention.

According to the concepts presented in Sec. 2.3, these contributions deal with the implementation of generic signals' formats to support message encoding/decoding and data storage in an artificial destination (databases or Design Repository).

Thus, a lot of work has been done on linguistic models to reduce the gaps between biology and engineering. However, in all these approaches, the common idea is to make engineers able to represent biological information in an engineering framework of reference, not to improve communication between biologists and engineers sharing the same project. As previously described, interdisciplinary communication suggests various actors from different fields acting as sources/transmitter, and receiver/destination which is not the case in the abovedescribed studies.

The second noise identified in Sec. 2.3.2 is the lack of common context (psychological noise). This communication brake focuses on the conceptual framework (commonness, scientific and cultural framework of reference) used as a prism to decode the signal and interpret the message. This type of impediment is particularly challenging with strong background differences. For instance, between researchers and industrial stakeholders since "they have different norms, standards, or values" [50].

Biomimetics is based on an analogical transfer of biological solutions into technological ones. As described in the literature, this analogical thinking is performed based on relations rather than feature [51] and so on interconnected systems rather than isolated ones [52]. To summarize, analogies are dealing with systems embedded within a field-related conceptual network. As a result, practitioners having a different background are unconsciously referring to distinct framework while trying to communicate. Where this variability of prisms represents an asset of interdisciplinary collaboration, it also leads to impediments preventing proper communication.

Based on this divide, Helms developed the four-box method, and the associated T-chart [53]. This tool aims to clarify design problems and biological analogues through contextual information. The Four-Box method is structured following the "four most frequently occurring descriptive elements of problem formulation." extracted from students' projects [53]. Through the definition of the problem's framework, solution search is supported, and 
analogical biological solutions can be compared through both their features (Functions, Specifications, and Performance Criteria) and their interacting environments (Operational Environment). The case study presenting the tool is performed by an interdisciplinary student team but on the communication part, "biologists report finding the tool more useful for communicating knowledge about biologically systems to their peers." [53], suggesting an intradisciplinary interest.

According to the concepts presented in Sec. 2.3, this contribution deals with the implementation of a generic signal format suitable for both biology and technology, as well as improving encoding/decoding through contextual data. The final goal is to improve the effectiveness of the search and selection steps.

Finally, the communication between biologists and engineers in biomimetic teams has been studied by Hashemi Farzaneh et al. [54] following a rather similar approach than the one we have used in this article. Through the description of features identified in representations from biology and product design, a graphic representation is suggested to improve communication between engineers and biologists. This article then follows the same research axis and considers alternative guidelines from the comparison of both processes and representations.

According to the concepts presented in the previous section, these contributions deal with the channel of communication (visual communication) and the format of encoding (graphic features).

Following the observations made on the scientific literature, the communication theories and the current approaches dealing with interdisciplinary gaps in biomimetics, Sec. 3 presents the research question and the hypothesis developed in this publication.

\section{Research Question and Hypotheses}

Biomimetics holds great potential but still has not reached its full potential as it struggles to spread. Biology-centered steps are identified in the literature as particularly challenging steps. To close the gap between the biological and engineering world, numerous articles recommend the integration of biologists. However, this approach is not without its own obstacles and communication between engineers and biologists appears as a crucial lever to consider. Several types on noises can be identified to characterize the communication brakes to solve.

First, the semantic noises. On that matter, the formalization of the data from biology has been the center of attention in knowledge transfer through tools but little research has been targeting communication itself.

Moreover, we would argue that semantic noises are crucial given that horizontal biologists are not integrated enough within design teams. We assume that a few weeks of shared work would be the best solution to assimilate specific concepts and create shared semantics. Once operational, horizontal biologists should act as a bridge between technical and biological experts. Where semantic tools can be a fundamental first step in communication, the stability of the team's composition between projects and so to maintain social bonds between actors [50] appears as a long-lasting strategy.

A second type of noise, psychological noises, more specifically cognitive dissonances (the lack of common framework of reference and message structure) also plays a part in communication issues within interdisciplinary teams. Some previous work focused on cognitive dissonances but overall this research axis remains mainly unexplored.

As a result, this article deals with biologists' and engineers' ways of reasoning and structuring information, as they witness their respective processes of converting message into signal. The research axis of this article is to question how to improve communication within interdisciplinary design teams, and more specifically, we wonder if we can define a common framework of reference to support communication between biologists and engineers in interdisciplinary biomimetic design teams?
The hypothesis of this article is that such a framework of reference would reduce cognitive dissonances, improving the ability of the team to communicate. Based on guidelines extracted from the comparison of visual representations and cognitive frameworks used in both fields, a framework is built. Within this framework, a tool is then designed to guide the reasoning and the generation of shared mental models to improve team's effectiveness [55]. The underlying assumption here is that cognitive dissonances represent an issue only if they disturb each other by overlapping. If cognitive dissonances are structured as complementary approaches then they represent the added value of these stakeholders, the abovementioned variability of prisms, and therefore the core of biomimetics reasoning. We assume that solving the lack of common framework of reference and message structure will lead teams to better communicate and to take advantage of these specificities through a synergic team functioning.

Through the design of this tool based on a framework of reference combining biological and engineering approaches, we propose a space for interdisciplinary interactions to support communication.

\section{Material and Methods}

This section summarizes the definition of various concepts used throughout the article and presents the method used to build the shared framework of reference.

4.1 Concepts Associated With the Study. As modeled in Sec. 2.3.1, interdisciplinary communication is strictly understood in this article as a two-way process between actors having a different background. In this context, and according to Choi's definition [56,57], interdisciplinarity is an approach which "analyses, synthesizes, and harmonizes links between disciplines into a coordinated and coherent whole." Thus, interdisciplinary teams are considered to be composed of interdependent contributing actors [58] with various backgrounds and structured as a "coordinated and coherent whole" to reach a common goal.

To assist communication within these teams, as well as their "coordinated and coherent" practices, this publication relies on the design of a shared framework of reference. From a generic standpoint, a framework of reference is understood in this article as " $a$ set of ideas, conditions, or assumptions that determine how something will be approached, perceived, or understood" [59]. The aim of this construct is to give a set of guidelines through which information can be properly interpreted and assimilated.

Stakeholders' mental representations of information, and so the subject of cognition, are defined as "mental models" [60]. Sharing a same framework should allow actors to position themselves in a common conceptual space, making them able to use similar and/ or complementary prisms of analysis [55].

Based on the framework, a tool incorporating the various guidelines is designed to create an interface through which the team can establish a shared mental model and reason in a synergic way. The aim of this tool is to support communication to reach a "transdisciplinary" practice of biomimetics. The mental model shared by the team is neither an engineering nor a biological model but "transcends each of their traditional boundaries" [56]. In this new conformation, actors share a "reciprocal interdependence driven by goals that include integrated input/output and affecting the other disciplines by reorientation" [58]. The team itself is then considered as a whole, having a common transdisciplinary field of expertise.

4.2 Methodology. The formulation of a common framework follows a methodology inspired from the previously described publications of Hashemi Farzaneh et al. [54] and Fayemi et al. [23] and synthesized as follows:

(1) Analysis of the field-specific frameworks.

(2) Comparison of key features: concepts, conditions, constraints, assumptions, etc. 
(3) Selection and/or combination of features and formulation of guidelines.

(4) Synthesis of the guidelines generating unified framework.

In the case of our study, the framework analysis (1) is based on the literature, the authors' experiences, and discussions with experts. Key features are then extracted into two aspects, visual representations and processes (2). The formulation of guidelines (3) follows elements extracted from the communication literature, the specificities of biomimetic practices, and the hypothesis of this article. Guidelines composing the framework are then synthesized in Table 3 (4).

Following this first phase, we designed LINKAGE through the embedment of the guidelines composing the new framework. LINKAGE aims to support the synergic reasoning and communication of team members through the collaborative modeling of shared representations of problems and solutions.

\section{Formalization of the Common Framework}

To identify key features to turn into structuring guidelines, we studied the processes generating the data used in biomimetic projects. The unified biomimetic problem-driven process [12] is taken as a reference for biomimetic processes and a generic biological research process as described by Bernard et al. [61] is taken as a reference to study biological research processes (phase 1, Sec. 4.2). Features are then listed and compared with underline cognitive dissonances between actors (phase 2, Sec. 4.2). Based on this comparative analysis, guidelines are formulated (phase 3, Sec. 4.2).

Following the same methodology, graphic representations are analyzed (phase 1, Sec. 4.2) and compared (phase 2, Sec. 4.2) to validate features extracted from processes. Additional guidelines are also formulated (phase 3, Sec. 4.2).

5.1 Analysis of the Field-Specific Frameworks and Comparison of Key Features on Processes. The overall idea of engineering design lies in the ability of design teams to create a system performing a given set of functions. Function is defined as the "general input/output relationship of a system whose purpose is to perform a task" or, at the early stages of the process, as the "abstract formulation of the task, independent of any particular solution" [62]. The term "system" is considered after De Rosnay's definition, "A system is a set of elements in dynamic interaction, organized according to a goal" [63].

Design processes thus guide design teams from a design brief to a product which functions answer initial requirements. This brief is based on client/company's understanding of "what products would be the most likely to be purchased by consumers?", or on larger scale "human needs/challenges" [64]. Design practice then appears subjective and profoundly dependent on the perception of needs by clients, and so ultimately users. The approach intrinsically depends on design choices leading to the variability of products designed to perform the same task. From a technical standpoint, the main validation parameter of these choices is the compliance with the product requirements and from a strategic and economic standpoint it's the consumers' acceptance, and so the commercial success. Whether they solve a problem, or offer new functionalities without an original problem, the rationale behind products then appears as the provided service, the functions at the users' disposal. As Simon stated "The engineer, and more generally the designer, is concerned with how things ought to be (...) in order to attain goals, and to function" [65].

In biological research, projects emerge from observations and the identification of a missing piece of biological knowledge. The choice between research axes appears subjective because highly dependent on funding, but the research results are supposed to be inherently objective. Biological research process has the fundamental aim of answering a research question, in the words of Claude Bernard, "An experimenter's mind must be active, i.e., must question nature" [61]. Comparing with design, biological studies are "seeking the truth and approaching it as nearly as possible". Facing a research question, choices are called hypotheses and are tested through experiments. The rationale behind biology then appears to be knowledge. This knowledge can be turned into innovation in a second time, but the core output of biological science remains the understanding of living beings.

Based on 13 criteria, from the origin of projects to their final outputs, processes of references are then described in detail (phase 1, Sec. 4.2) (Table 1). These key features are then compared, and cognitive shifts are identified (phase 2, Sec. 4.2). Guidelines synthesizing the various criteria are then formulated (phase 3, Sec. 4.2). Five guidelines have been identified through the comparative analysis presented in Table 1.

Guideline A: Embed subjective elements in external constraints. We suggest engineers to embed subjective elements of the project (concepts 2 and 3, Table 1) as external constraints. Doing so, biologists may approach the problem with objective questions (concept 3 , Table 1), trying to understand how a biological system (concept 2 , Table 1) would react facing given constraints (concept 1 and 2 , Table 1).

Guideline B: Combine prescriptive and descriptive approaches. We suggest interdisciplinary teams to establish phases for prescriptive (concept 5, Table 1) reasoning leading to functional scenarios (concept 4, Table 1) describing the system-to-be (concept 6, Table 1) as if it was real (concept 6, Table 1) allowing, in a second phase, biologists to raise alternative technical questions (concept 4, Table 1) or to describe (concept 4, Table 1) biological solutions.

Guideline $C$ : Expose the cognitive links to bridge functional, structural, material and behavioral abstracted concepts. We suggest team mates to explain their reasoning (concept 8, Table 1) on a shared representation, allowing the various actors to make connection with their own, field-related, conceptual framework (concept 7, Table 1) and generate hypotheses to be turned into solutions (concept 9).

Guideline D: Present problems and solutions within their spatiotemporal contexts. In both fields, context is key. First, it dictates requirements for the design project and environmental constraints from a biological standpoint (concept 10, Table 1). Second, it ensures the solution's validation (concept 11, Table 1) and finally it underlines the possibility of evolving conditions, questioning the validity and adaptability of the biological/technical systems (concept 12, Table 1).

Guideline E: Dedicate spaces for both product design and knowledge gathering while supporting their synergic contribution. Since biologists' system of reward is based on knowledge and engineers' system of reward is based on the generation of well-functioning products (concept 13, Table 1), we suggest interdisciplinary teams to implement a biomimetics innovation strategy along with a knowledge management strategy. Stakeholders should feel recognized for both their team and field-specific work to prevent frustration while maintaining a collaborative, non-competitive, team spirit.

Section 5.2 then presents several biological graphic representations that have been analyzed and compared with intermediate representations from engineering design [66]. Since biological process is similar to most scientific processes, this section presents the identification of additional, more biology-specific, guidelines.

5.2 Analysis of Biological Information Representation. In research, communication mainly occurs through conferences or through the encoding of results in the form of scientific articles. Within biological articles, figures representing biological systems synthesize biological knowledge and thus holds a fundamental role in communication. Figures data measurements, such as graphs, matrix, etc. were not studied in this publication since they do not appear specific to biology. Through the literature, the authors' experience in biology and the discussion with biology teachers-researchers, we pointed out three common biological types of 
Table 1 Comparative analysis on processes and guidelines synthesis

\begin{tabular}{|c|c|c|c|c|}
\hline Concepts & In Engineering & In Biology & Cognitive shifts & Guidelines \\
\hline 1. Origin of a project & $\begin{array}{l}\text { Potential profit from the product's } \\
\text { sales }\end{array}$ & $\begin{array}{l}\text { Absence of knowledge, and/or financial } \\
\text { incentives toward a biological truth }\end{array}$ & \multirow{3}{*}{$\begin{array}{l}\text { Where projects in engineering are } \\
\text { based on strategic choices and target a } \\
\text { consumer, projects in biology are } \\
\text { based on scientific knowledge and } \\
\text { target a scientific truth }\end{array}$} & \multirow[t]{3}{*}{$\begin{array}{l}\text { Guideline A: Embed subjective elements in } \\
\text { external constraints }\end{array}$} \\
\hline 2. Input of the project & Client/marketing brief & $\begin{array}{l}\text { A biological system or phenomenon to } \\
\text { understand }\end{array}$ & & \\
\hline 3. Project orientation & Subjective & Objectives & & \\
\hline 4. Type of problem & $\begin{array}{l}\text { "How to design a system that } \\
\text { perform" + function? }\end{array}$ & $\begin{array}{l}\text { "How do" + biological system + perform } \\
\text { a function? }\end{array}$ & \multirow{3}{*}{$\begin{array}{l}\text { Where biologists deeply characterize } \\
\text { the system to describe its functioning, } \\
\text { engineers adopt a functional } \\
\text { reasoning and look to prescribe a } \\
\text { system that would represent a solution }\end{array}$} & \multirow[t]{3}{*}{$\begin{array}{l}\text { Guideline B: Combine prescriptive and } \\
\text { descriptive approaches }\end{array}$} \\
\hline 5. Type of reasoning & Prescriptive & Descriptive & & \\
\hline 6. System studied in the project & $\begin{array}{l}\text { Conceptual: The studied system } \\
\text { doesn't exist yet }\end{array}$ & Concrete: The studied system is observed & & \\
\hline 7. Solving process' inputs & $\begin{array}{l}\text { Abstracted function and associated } \\
\text { technical problems }\end{array}$ & $\begin{array}{l}\text { Abstracted biological generic concepts } \\
\text { associated with a set of rules }\end{array}$ & \multirow{3}{*}{$\begin{array}{l}\text { Both profiles use abstraction to solve } \\
\text { their problem. However, where } \\
\text { engineers use abstraction as a } \\
\text { formalized prerequisite for analogical } \\
\text { thinking, biologists, through their } \\
\text { reasoning, unconsciously abstract the } \\
\text { various parts of an existing system to } \\
\text { generate hypotheses on their potential } \\
\text { functional interaction, and ultimately } \\
\text { generate knowledge }\end{array}$} & \multirow{3}{*}{$\begin{array}{l}\text { Guideline } C \text { : Expose cognitive links to bridge } \\
\text { functional, structural, material, and } \\
\text { behavioral abstracted concepts }\end{array}$} \\
\hline 8. Solving process & $\begin{array}{l}\text { For biomimetics, analogical reasoning } \\
\text { through the identification of } \\
\text { biological models sharing the same or } \\
\text { close abstracted function/technical } \\
\text { problems }\end{array}$ & $\begin{array}{l}\text { Based on concepts' interaction and } \\
\text { associated biological principles. } \\
\text { Resolution in the conceptual space. } \\
\text { Analogical reasoning may also be used } \\
\text { between biological studies }\end{array}$ & & \\
\hline 9. Solving process output & Identified solution & Generated hypothesis & & \\
\hline 10. Embodiment & $\begin{array}{l}\text { Generation of numerical models and } \\
\text { prototype to verify that requirements } \\
\text { are met }\end{array}$ & $\begin{array}{l}\text { Design of a protocol and experiment } \\
\text { based on the hypothesis. Identification of } \\
\text { data to be measured }\end{array}$ & \multirow{3}{*}{$\begin{array}{l}\text { Most of the time, biologists would not } \\
\text { perform biological experiments } \\
\text { during biomimetic design processes } \\
\text { and will directly look at knowledge. } \\
\text { However, the system's adequacy and } \\
\text { properties will be tested. For the tests } \\
\text { to be relevant, contextualization in } \\
\text { both space and time/state appears } \\
\text { required }\end{array}$} & \multirow[t]{3}{*}{$\begin{array}{l}\text { Guideline D: Present problems and solutions } \\
\text { within their spatiotemporal context }\end{array}$} \\
\hline 11. Testing phases & $\begin{array}{l}\text { Test both if the solution performs } \\
\text { efficiently the function and what are } \\
\text { users' feedback }\end{array}$ & $\begin{array}{l}\text { Test if the model (in vitro/in vivo) reacts } \\
\text { the way it was predicted }\end{array}$ & & \\
\hline 12. End of the project steps & $\begin{array}{l}\text { The design of the product is } \\
\text { improvement. The detailed design and } \\
\text { industrialization phase then begin }\end{array}$ & $\begin{array}{l}\text { Based on the results, the hypothesis is or } \\
\text { is not validated, the researcher generates a } \\
\text { rapport or an article to explain its findings }\end{array}$ & & \\
\hline 13. Final output & A product & An increase of knowledge & $\begin{array}{l}\text { Where a system is the final outputs in } \\
\text { product design, the system is the } \\
\text { initial input in biology. Where } \\
\text { information and knowledge are the } \\
\text { inputs in product design, they are the } \\
\text { outputs in biology }\end{array}$ & $\begin{array}{l}\text { Guideline E: Dedicate spaces for both } \\
\text { product design and knowledge gathering } \\
\text { while supporting their synergic contribution }\end{array}$ \\
\hline
\end{tabular}




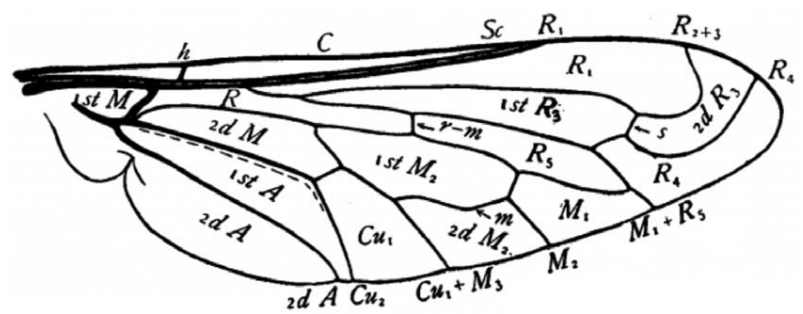

Fig. 3 Observational representation of the wings of Pantarbes, a genus of bee. From Comstock, "The Wings of insects," 1918, (fig. 368).

representation that we characterized as observational, nested, and dynamic.

5.2.1 Observational Representations. This first type of representation reflects biologists' observations. Among these are observational drawings (through microscopes or with the naked eye) allowing biologists to describe biological specimens, present results and characterize newly discovered species. Figure 3 gives an example of an observational drawing describing the anatomic specificities of the wings of Pantarbes, a genus of bee.

Observational drawings are nowadays strongly supplemented with numeric alternatives, photographs, electronic microscopy, $2 \mathrm{D}$ or $3 \mathrm{D}$ imaging, etc.

Among other fields, observational representations are used in animal or vegetal anatomy, histology, morphology, etc.

At a conceptual level, this type of representation underlines the necessity for biologists to communicate on the biological concept of form [67].

5.2.2 Nested Representations. The second type of representation aims to describe organization of biological structures at multiple levels. These schematics thus represent, on the same figure, different magnifications, zooming in a nested biological structure in order to point out its complex hierarchical organization. These representations are often used in anatomic descriptions to give insights on the origin of systems' properties. Figure 4 gives the example of the various levels of genetic condensation.

At a conceptual level, these representations deal with the biological concept of structure [67].

5.2.3 Dynamic Representations. Dynamic representations can be divided in at least two categories. The first category represents biological entities in successive states, explicitly modeling given changes of state and so dynamic phenomena. Analyzing these representations, we determined at least four main dynamic patterns that can be distinguished: cyclical, acyclical, mixed, and multi-cyclical.

In cyclical processes, biological systems return to their original state. Figure 5 presents an example of a cyclical process with the

(a)

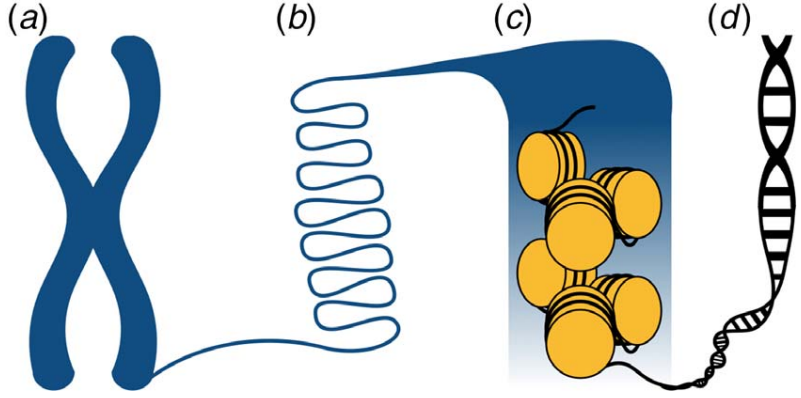

Fig. 4 Nested representation of genetic material: (a) chromosomes, (b) $300 \mathrm{~nm}$ chromatin loops, (c) $30 \mathrm{~nm}$ chromatin, and (d) $2 \mathrm{~nm}$ double-strained DNA (a) Voltage-gated channe

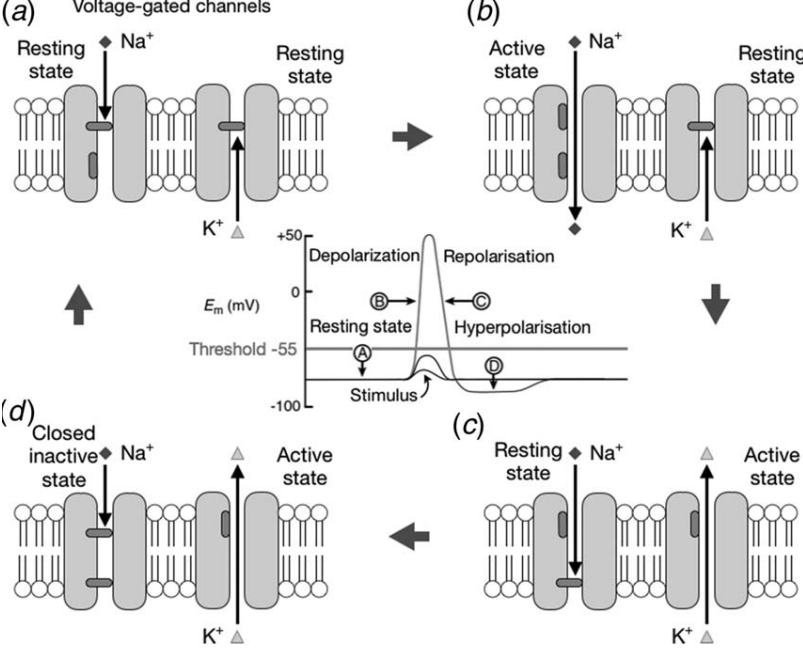

Fig. 5 Example of a cyclical process, here the behavior of ionic channels during the propagation of an action potential. Based on Ref. [68].

behavior of ionic channels during the propagation of an action potential. The separation of ions, their specific flows, and their combined transports allow the propagation of an action. Processes with a cyclical pattern often constitute functional sub-units.

Multi-cyclical pattern can also be observed. During action potential generation phase, a first type of cycle can occur when the stimulation remains under a threshold (failed initiation on the center of Fig. 5). Once the threshold is exceeded, an action potential is generated, and the second type of cycle emerges as previously presented. The overall phenomenon is then multi-cyclical.

In acyclical processes, biological systems undergo irreversible changes (evolutionary process of species, the growth of an individual, etc.) and then do not usually return to their original state (Fig. 6).

Acyclical processes are often the result of several biological functioning units as they induce deep and synchronized modifications of the biological entities: growth, differentiation, evolution, etc.

Finally, mixed processes are identified. For example, a cyclical process, such as the cardiac cycle, might evolve progressively through time, strengthening thanks to exercises, or evolve in a more sudden way in the case of a stroke. As all cyclical processes ultimately change because of aging, the combination of cyclical and acyclical patterns is the most complex, but the most accurate one.

Since a biological structure can be highly variable between two individuals at the same age, the concept of time is highly relative in biology. Biologists then rather refer to states instead of time when describing a biological process. For example, a highly damaged lung could be caused by 20 years of smoking or caused by 40 years of extreme work conditions. What we consider here is the state of the lungs' degradation process, not its age per se. However, duration can be, and often is, critical in processes. As a
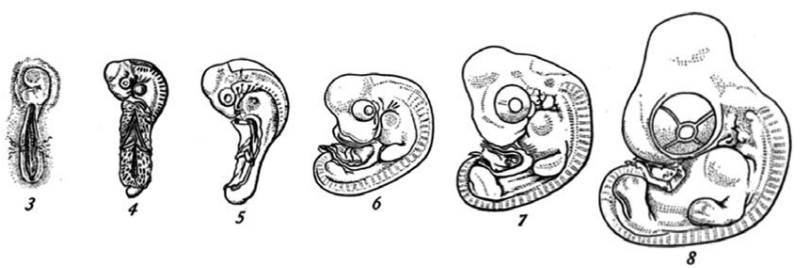

Fig. 6 Example of an acyclical process representation, six of the developing stages of a chick. Image by Franz Kreibel adapted from Ref. [69]. 




Fig. 7 Example of a generic molecular pathway, from signal fixation (molecule A) to the secretion of a response protein (protein p)

result, biologists often artificially determine $t=0$ at the starting point of processes with a cyclical pattern.

In the second category of dynamic representation, the different states are not explicitly represented but are suggested in the schematics, mainly through arrows (Fig. 7).

They focus on the dynamics of interactions between various elements (molecular, living organisms, external parameters, etc.). For example, they model molecular pathways or ecosystemic relationships for example. These schematics allow the representation of successive change of states, like chain reactions in cellular biology or microbiology. Combined with the recent emergence of computational approaches, these representations lead to the emergence of the field of systems biology that would not be studied in this article. The dynamic type of representation thus represents the biological concept of function [67].

It has to be underlined that other types of representations exist in biology, such as phylogenetic trees, models in systems biology [70], etc. Nonetheless, through this quick description of three types of representation, the importance of a multiparameter prism (scales, interactions, states) appears as a key aspect of biological representations.

In biology, it is a well-known fact that forms and structures allow function [67]. The representations abovementioned lead biologists to structure specific forms in order to consider functions, such as "dealing with internal and external energy" or "managing information" [71].

In engineering, the types of encoding are strictly characterized, they follow well-defined structures depending on the phases of the project and the required level of abstraction. In order to validate the previously identified cognitive shifts, the characteristics of these intermediate representations [66] have been compared with the observations made on biological representations.

\subsection{Comparison of Biological and Engineering} Representations. This section presents several key concepts explaining potential cognitive dissonances (phase 1, Sec. 4.2) and compares them (phase 2, Sec. 4.2) to synthesize guidelines (phase 3, Sec. 4.2) (Table 2).

Four new guidelines are thus synthetized. Guideline F: Consider system's evolution through state-based reasoning to represent functions. Biological literature uses state-based reasoning to represent the dynamics of processes leading to functions. We suggest engineers to formalize problems in a similar format to align biological

Table 2 Comparative analysis on graphic representation and guidelines synthesis

\begin{tabular}{|c|c|c|c|c|}
\hline Concepts & In engineering & In biology & Cognitive shifts & Guidelines \\
\hline $\begin{array}{l}\text { 1. Objective of the } \\
\text { representation }\end{array}$ & $\begin{array}{l}\text { Explain the objectives to meet } \\
\text { and how to design a system or } \\
\text { parts of the system performing } \\
\text { the determined functions }\end{array}$ & $\begin{array}{l}\text { Represent the characteristics, } \\
\text { structures, and functioning of } \\
\text { biological organism and } \\
\text { phenomena in order to } \\
\text { describe observations, } \\
\text { hypothesis, or results }\end{array}$ & $\begin{array}{l}\text { Technical representations } \\
\text { explain what is expected and } \\
\text { prescribe how to meet these } \\
\text { expectations where biologists' } \\
\text { representations describe } \\
\text { biological systems and the } \\
\text { way they function }\end{array}$ & $\begin{array}{l}\text { Validate the guideline } B \\
\text { (from Table 1): Prevent } \\
\text { noises coming from } \\
\text { overlapping channel of } \\
\text { communication }\end{array}$ \\
\hline $\begin{array}{l}\text { 2. Concept of } \\
\text { functions }\end{array}$ & $\begin{array}{l}\text { Represents the product's } \\
\text { legitimacy (client brief, } \\
\text { Octopus diagram, etc.) }\end{array}$ & $\begin{array}{l}\text { Represents the consequences } \\
\text { of the forms' and structures' } \\
\text { evolution through states } \\
\text { (various patterns) }\end{array}$ & $\begin{array}{l}\text { Where, in biology structured } \\
\text { forms allow functions and } \\
\text { give an evolutive advantage to } \\
\text { biological systems, in } \\
\text { engineering, structures and } \\
\text { forms are design to perform a } \\
\text { pre-established function }\end{array}$ & $\begin{array}{l}\text { Guideline } F \text { : Consider } \\
\text { system's evolution } \\
\text { through state-based } \\
\text { reasoning to represent } \\
\text { functions }\end{array}$ \\
\hline $\begin{array}{l}\text { 3. Concept of } \\
\text { structures }\end{array}$ & $\begin{array}{l}\text { Association of functional } \\
\text { sub-units from various } \\
\text { sub-systems (FAST diagram, } \\
\text { etc.) }\end{array}$ & $\begin{array}{l}\text { Deeply intricate association of } \\
\text { elements of the biological } \\
\text { system [72] developed along } \\
\text { the evolutionary process }\end{array}$ & $\begin{array}{l}\text { Where engineers reason on } \\
\text { structure with a sequential } \\
\text { approach linked with } \\
\text { subfunctions, biologists } \\
\text { zoom-in biological nested } \\
\text { structure to understand how } \\
\text { functions are performed }\end{array}$ & $\begin{array}{l}\text { Guideline } G \text { : Model } \\
\text { systems through nested } \\
\text { structures }\end{array}$ \\
\hline $\begin{array}{l}\text { 4. Concept of } \\
\text { forms }\end{array}$ & $\begin{array}{l}\text { Final embodiment of the } \\
\text { technical elements performing } \\
\text { the subfunctions (CAD, etc.) } \\
\text { (final steps) }\end{array}$ & $\begin{array}{l}\text { Initial observation of a } \\
\text { biological entity in the real } \\
\text { world (observational } \\
\text { representation, etc.) (early } \\
\text { steps) }\end{array}$ & $\begin{array}{l}\text { Where form's representation } \\
\text { in engineering is an } \\
\text { embodiment of subfunctions, } \\
\text { form's representation in } \\
\text { biology is a clue toward the } \\
\text { solving of a research question }\end{array}$ & $\begin{array}{l}\text { Guideline } H \text { : Be specific } \\
\text { on forms }\end{array}$ \\
\hline $\begin{array}{l}\text { 5. Systemic } \\
\text { approach }\end{array}$ & $\begin{array}{l}\text { Taking a systemic standpoint } \\
\text { increases the number of } \\
\text { constraints and so the } \\
\text { functional complexity }\end{array}$ & $\begin{array}{l}\text { The resolution of a biological } \\
\text { problem is intrinsically linked } \\
\text { with the consideration of } \\
\text { various systemic levels, and of } \\
\text { environmental elements [73]. } \\
\text { Living systems are complex } \\
\text { systems }\end{array}$ & $\begin{array}{l}\text { We can see a shift toward the } \\
\text { consideration of the systemic } \\
\text { reasoning which represents an } \\
\text { increase of complexity in } \\
\text { engineering but a requirement } \\
\text { to solve problems in biology }\end{array}$ & $\begin{array}{l}\text { Guideline I: Support a } \\
\text { systemic standpoint }\end{array}$ \\
\hline
\end{tabular}


and technical visual channels along with signals' encoding (concept 2, Fig. 2).

Guideline G: Model systems through nested structures. We suggest using nested modeling to support communication by aligning visual channels and by creating a conceptual link between functional sub-units and biological sub-systems at various organizational scales (concept 3, Fig. 2).

Guideline $H$ : Be specific on forms. Forms are the first visible clues toward the understanding of biological phenomenon. Where biologists may understand forms as characteristic features, engineers may also analyze forms from their technical standpoint. Doing so, they can bring additional expertise, on fluids dynamics for instance, and identify functional properties. Synergic practices should then lead to the creation of new communication paths by allowing practitioners to identify which messages, and types of signal, are relevant, and for which teammates (destination) (concept 4, Fig. 2).

Guideline I: Support a systemic standpoint. We suggest adopting a systemic standpoint to align the teammates' shared mental models through an increasing number of characterizing conceptual links (concept 5, Fig. 2).

Section 5.4 concludes Sec. 5 and summarizes the main elements structuring the common framework of reference (phase 4, Sec. 4.2).

5.4 Synthesis on the Guidelines Structuring the Common Framework of Reference. Through the comparative analyses presented in Sec. 5, nine guidelines have been formalized to structure a common framework of reference to assist interdisciplinary biomimetic design teams' communication and practice.

In the words of Simon "The natural sciences are concerned with how things are (...) design on the other hand is concerned with how things ought to be" [65]. Among his main difference is often referred to as "prescriptive" versus "descriptive" reasonings in the literature [37].

First, reasoning shifts regarding processes have been identified on processes and summarized into five guidelines (Table 1).

The analysis then focused on visual communication channels, identified in the literature as a potential lever for improving communication [54], and questioned messages' encoding/decoding, signal's characterization, and mental models. Four more guidelines have thus been added to the common framework of references.

The synthetized framework combines both ways of looking at problems or solutions to support biologists' integration, interdisciplinary communication, and promote a synergic teamwork:

- Guideline A: consider subjective elements as embedded in external constraints.

- Guideline B: combine prescriptive and descriptive approaches.

- Guideline C: expose cognitive links to bridge functional, structural, material, and behavioral abstracted concepts.

- Guideline D: present problems and solutions within their spatiotemporal contexts.

- Guideline E: dedicate spaces for both product design and knowledge gathering while supporting their synergic contribution.

- Guideline F: consider problem/solution dynamics through a state-based evolution

- Guideline G: model systems through nested structures

- Guideline H: be specific on forms

- Guideline I: support a systemic standpoint

Based on this common framework of reference established, Sec. 6 describes the designing of LINKAGE, a new tool destined for biomimetic interdisciplinary team.

\section{LINKAGE}

Link an Interpretation based on Natural science Know-how with an Applied Goal from Engineering (LINKAGE) is a tool intended to design project-specific common frameworks based on the various structuring generic guidelines identified in Sec. 5 .

6.1 LINKAGE's Goals. LINKAGE's first goal is to assist communication between "classic" design teams and horizontal biologists.

Its second goal is to optimize the biomimetic design process by guiding the reasoning of the practitioners.

Lastly, LINKAGE aims to offer a way to store both structured information, and coupled technological challenge and biological solution, to capitalize on biomimetic studies, maximize their profitability, and recognize the increase of knowledge as an objective (Guideline E).

The long-term goal of this tool is to increase biomimetic design teams' effectiveness and to contribute to biomimetics implementation and spreading.

6.2 LINKAGE's Formalization. LINKAGE's building is presented through examples and following the steps of the unified problem-driven process [12]. Guidelines from the common framework used to design LINKAGE are explicitly identified. Their embodiments are then summarized at the end of Sec. 6 (Table 3).

6.2.1 Step 1: Problem Analysis. As presented previously, technology pull processes are based on design problems. For example, how to design a system that selectively filter a liquid without clogging? usually comes from the following cognitive reasoning: Through time, residual elements of the filtered liquid accumulate at the filter's surface and clog it, as a result, how can we prevent this phenomenon? Following the guideline A, we embed this problem as external constraints. Since problems are dynamics, the modeling leads to scenarios. As guided by the guideline $F$, these scenarios follow state-based dynamics rather than linear time-based, dynamics. In order to visually represent the dynamics, states are linked with arrows. Teams may question the problem through the various patterns existing in biological representation (Sec. 5.2.3). Whatever the scenarios, LINKAGE suggest closing the loops to implement a homeostasis-based reasoning.

Applying this first step to our example, the original problem is decomposed in three states, "Initial state" (clean), "In use" (not clean but not clogged) and "Clogged" (not functional). The evolution pattern is acyclical if the filter is discarded after it clogged, it is cyclical if the filter is cleaned and reused. LINKAGE suggests looking at the problem through the second angle, allowing to reach back the initial state. Logically, the filter will be discarded eventually so the mixed pattern can be used to represent the whole life cycle of the system.

Facing this scenario, the design team can approach the problem from an objective standpoint since the subjective orientation is already imposed by the states. In this first step, the system is not characterized yet, the design problem is.

6.2.2 Step 2 and 6: Abstraction of Design Problems or Biological Solutions. Step 2 and 6 of the process both aim to model systems. As a result, they are described simultaneously.

Following the guideline G, the LINKAGE tool allows systems' representation at multiple organization scales leading to a nested structure. Based on the guideline I, this approach is also associated with systemics reasoning, more specifically the ontological axis component [74].

In practice, LINKAGE presents at least three nested systemic levels: the super-system, system, and subsystem. Yet, the tool suggests considering further levels. Within LINKAGE, specific spaces dedicated for each systemic level questions users, leading them to deeply characterize the various elements to consider (guideline $H$ ) and their interconnections (guideline $C$ ).

Interestingly, during these phases LINKAGE's inputs can come from functional analysis tools such as "Octopus diagram" from the APTE method (Fig. 8) which are well-known bydesign teams. 


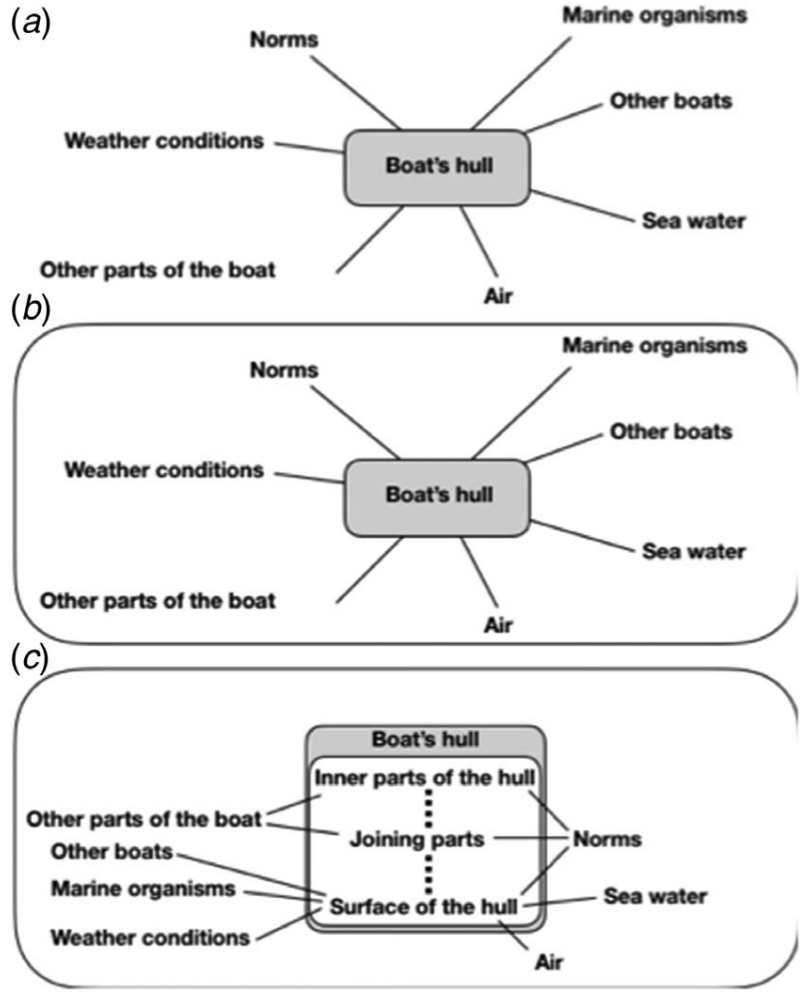

Fig. 8 From a functional analysis representation to a nested standpoint. Interacting sub-systems are connected through dashed lines.

It should then be easily compatible and implementable with design team's preexisting practice.

One interest of LINKAGE is to force design team to further consider the space of the super and sub-systems and so create interconnection at multiple scales. For example, "how are weather conditions impacting a plane's wing? On which subparts? On which organizational layers?" (guideline G).

Based on this new nested representation, users can model either technological systems (step 2) or biological systems (step 6), through textual descriptions and structured graphic representations (observational representation, blueprint, etc.) (Fig. 9).

Based on the guideline $F$, the system's dynamics in implemented through the states and patterns previously defined. System's functional features linked with the problem/solution are thus represented.

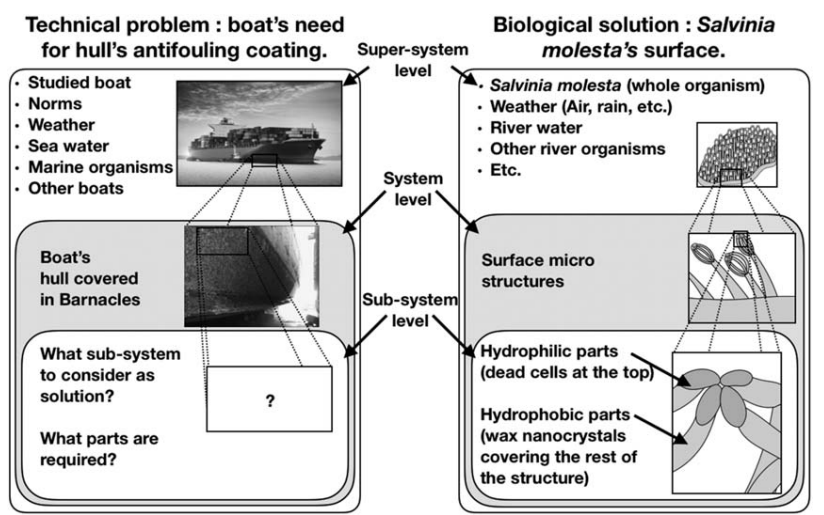

Fig. 9 Example of LINKAGE's formalization focused on levels of organization, for the surface of a boat's hull and the surface of Salvinia molesta. Pictures based on Ref. [75].

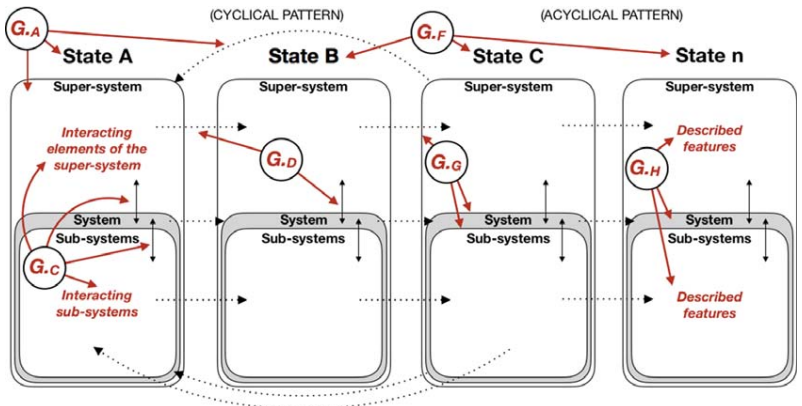

Fig. 10 Empty version of a LINKAGE representation with guidelines' embodiments ( $G_{. A}, G_{. C}, G_{. D}, G_{. F}, G_{. G}$, and $\left.G_{. H}\right)$

If we take the example of the filter previously used, the filter and liquids are linked during the structural description, but the filter's function only appears once the liquid get from one side (state 1) to the other side (state 2).

Figure 10 illustrates a mixed LINKAGE representation composed of three systemic levels, a three-step cyclical phenomenon (A, B and C) and an acyclical phenomenon of $n-2$ states. Guidelines which embodiments can be directly perceived on the representation are specified in red $\left(G_{\cdot A}, G_{\cdot}, G_{\cdot D}, G_{\cdot F}, G_{._{G}}\right.$ and $\left.G_{\cdot_{H}}\right)$ (Fig. 10). Through this state-based functional reasoning, LINKAGE allows interdisciplinary design teams to express the system's evolution in a framework that is more coherent with biological processes. Doing so, LINKAGE assists teammates communication through the implementation of a common format (visual representation) and guides the abstraction of external constraints, functional features, and structural elements during modeling steps.

To summarize, LINKAGE aims at allowing users to visualize various systemic levels, along with their interactions, at various states. LINKAGE's final structure combines elements from both fields and supports the constitution of a shared space of representation and mental models (Table 3 ).

6.3 LINKAGE, a Tool Fitting the Current Biomimetic Conceptual Framework. Various biomimetic innovation axes are characterized in the literature. Existing theoretical concepts can be linked with the structure of LINKAGE (Table 4).

The biological concept of function [67], which is the basis of engineering reasoning, appears as the synthesis of the whole representation as the form and structure allow the system to fulfil its function through processes.

\section{Intended Contributions}

Through the description of LINKAGE's potential outputs on communication, team collective reasoning, modeling, and abstraction, this section describes the main expected contributions of the tool.

7.1 Contributions to Prevent the Cognitive Dissonance. Cognitive dissonances, identified in the literature as a main source of communication noises (Sec. 2.3.2), is the disruptive overlapping of variable cognitive frameworks (cultural, reasonings habits, practical goals, etc.).

When unusual teammates are integrated in design teams, no specific spaces are dedicated for them at first. Cognitive dissonances then appear to be linked to the fact that several people are trying to do the same things at the same time with different frameworks without acknowledging or understanding these differences. So "Where can I (and my ideas) fit?" may be the first question horizontal biologists will ask themselves. Indeed, since the design reasoning and methodological framework were established as working 
Table 3 Guidelines' embodiment on LINKAGE tool

\begin{tabular}{|c|c|}
\hline Guidelines & Embodiment \\
\hline Guideline A: Embed subjective elements in external constraints & $\begin{array}{l}\text { Characterization of the super-system and of the system's various states } \\
\text { (Fig. 10, } \mathrm{G}_{\text {.A }} \text { ) }\end{array}$ \\
\hline Guideline B: Combine prescriptive and descriptive approaches & $\begin{array}{l}\text { Separation in space (embed constraints versus description on multiple levels) } \\
\text { and separation in time (phases of use) }\end{array}$ \\
\hline $\begin{array}{l}\text { Guideline } C \text { : Expose cognitive links to bridge functional, } \\
\text { physicochemical and behavioral abstracted concepts }\end{array}$ & $\begin{array}{l}\text { The network of concepts designed at different scales of the model and at } \\
\text { various states of the problem/solution (Fig. 10, } G_{. C} \text { ) }\end{array}$ \\
\hline $\begin{array}{l}\text { Guideline D: Present problems and solutions within their } \\
\text { spatiotemporal contexts }\end{array}$ & $\begin{array}{l}\text { Definition of super-systems (depend on space and time) and states (depend on } \\
\text { duration) (Fig. 10, } \mathrm{G}_{\text {.D }} \text { ) }\end{array}$ \\
\hline $\begin{array}{l}\text { Guideline E: Dedicate spaces for both product design and knowledge } \\
\text { gathering while supporting their synergic contribution }\end{array}$ & $\begin{array}{l}\text { Capitalization of the results through a database or an ontology based on } \\
\text { models formalized with LINKAGE. Recognize generated knowledge for their } \\
\text { scientific value }\end{array}$ \\
\hline $\begin{array}{l}\text { Guideline F: Consider system's evolution through state-based } \\
\text { reasoning to represent functions }\end{array}$ & Evolution patterns through states (Fig. 10, $\mathrm{G}_{. \mathrm{F}}$ ) \\
\hline Guideline $G$ : Model systems through nested structures & Nested structure and interaction through double-head arrows (Fig. 10, G.G) \\
\hline Guideline $H$ : Be specific on forms & $\begin{array}{l}\text { A specific space is dedicated for each level to characterize the features of } \\
\text { involved elements (Fig. } 10, G_{. H} \text { ) }\end{array}$ \\
\hline Guideline I: Support a systemic standpoint & $\begin{array}{l}\text { Based on Le Moigne [74]: } \\
\text { The nested structure refers to the ontological axis } \\
\text { The evolution patterns through states refers to the functional axis (cyclical } \\
\text { pattern) and the genetic axis (acyclical pattern) } \\
\text { The network of concepts that can be abstracted refers to the teleological axis }\end{array}$ \\
\hline
\end{tabular}

wholes, no pieces appeared missing and so no spaces were available.

Through the formalization of an expended common framework (Sec. 5), new spaces are likely to become available, allowing the integration of alternative reasonings and approaches represented by horizontal biologists. This step is intended to recognize fieldspecific differences, supporting the avoidance of disruptive overlaps.

LINKAGE structures the combination of prescriptive and descriptive approaches and is expected to guide the teams' practice toward the identification of several layers of information and several use phases on a single shared representation.

The first step of the biomimetic design problem is the definition of the design problem and can be associated with the generic question "what do we actually want to do?". Such questioning is linked with a prescriptive approach. However, relevant design objectives rely on context and requirements and so the definition of elements and their interaction at various systemic levels. This descriptive approach can be represented by the following question: "What is it that we are looking at?". The implementation of a dynamic evolution of the model and the characterization of the elements' interaction involved in the system's change of state should lead the team to define the functions through a descriptive standpoint: "What does the system need to do to reach the following state in the given context?" Prescriptive design requirements are then embedded in the context.

Foundations of the project may thus be determined in a shared framework, and the analysis of the model should lead to the technical problems by wondering "how to get from state $n$ to $n+1$ at each systemic level?"

Again, a descriptive approach is expected to be used by the team during this step, which should lead to the abstraction of the design problem on several layers of analysis. Keeping the interactions' patterns while abstracting the elements composing the system, sub, and super-system levels should then allow the design team to perform more easily an overall abstraction of the technological problems.

The following step in the biomimetic design process is the transposition to biology. Based on the context and abstracted elements, the design team should be able to describe a biological solution space. Thanks to its states-based and nested structure, this space definition is intended to depend not only on prescriptive functional constraints but also on the descriptive contextual constraints. Each super-system that includes our systemic level of interest can bring information.

The source of biological models may either be a horizontal biologist or already existing tools. We will not go further into details on that subject in this article.

Table 4 Synthesis of biological and biomimetic concepts alignment with LINKAGE's design

\begin{tabular}{|c|c|c|}
\hline LINKAGE & Biology & Biomimetics \\
\hline Description of elements at each level of organization & Form [67] & $\begin{array}{l}\text { Form }[1] \\
\text { Structure [23] } \\
\text { Morphology [24,54] }\end{array}$ \\
\hline $\begin{array}{l}\text { Interactions within and between systemic levels, } \\
\text { double-head arrows }\end{array}$ & Structure [67] & $\begin{array}{l}\text { (Eco)system [1] } \\
\text { Relational [54] } \\
\text { Pattern of organization [23] }\end{array}$ \\
\hline $\begin{array}{l}\text { Pattern of evolution between states and single-head } \\
\text { arrows }\end{array}$ & Processes [67] & $\begin{array}{l}\text { Change }[54] \\
\text { Processes }[1,23]\end{array}$ \\
\hline Analyses of representations made with LINKAGE & $\begin{array}{l}\text { Definition of internal or external constraints } \\
\text { and of solving strategies }\end{array}$ & $\begin{array}{l}\text { Abstraction of technical problems (step 2) or } \\
\text { biological solutions (step 6) [64] }\end{array}$ \\
\hline
\end{tabular}


Table 5 Comparison of LINKAGE and already existing biomimetic tools on several methodological characteristics

\begin{tabular}{|c|c|c|}
\hline & Existing tools & Linkage \\
\hline Specific aim & $\begin{array}{l}\text { Gives a way to perform one of the biomimetic } \\
\text { process' step }\end{array}$ & $\begin{array}{l}\text { Structure the information gathered by the team and guide the communication } \\
\text { process to reach a synergic reasoning }\end{array}$ \\
\hline Fitting user profile & Mostly unidentified & Full potential with interdisciplinary biomimetic teams \\
\hline Conceptual framework & Engineering design and biomimetics & $\begin{array}{l}\text { Common framework of reference combining, engineering design, } \\
\text { biomimetics, and biology through structuring guidelines }\end{array}$ \\
\hline Scope & Mostly step specific & Contribution identified at least during steps $2,3,6$, and 7 \\
\hline
\end{tabular}

Once a biological model is identified, it should be possible to model it on the exact same framework, using the same approach, then with the technological problem. From the biological model, the team is again oriented toward a descriptive standpoint. The team will then face the following question: "How does the biological model perform this function?" (descriptive).

The reversal of the expert roles between engineers and biologists at this specific step is expected to be supported by LINKAGE and should then be acknowledged by the team. As a result, even if they adopt different roles, team members should be able to represent information on a shared representation. LINKAGE is then intended to bring an expression support for horizontal biologists to be heard and understood while the team shares a common mental model.

In a rather similar way than with the technological aspects, the biological model may be analyzed and compared with the design problem. Horizontal biologists should then ensure the scientific relevance of gathered data while the rest of the team is guided to define the proper level of abstraction of the biological strategies. The similarity of representation of both design problem and solution should ease the transfer toward technological application leading the team back to a prescriptive reasoning, "based on the chosen biological model, how to design a system fitting our functional requirements?".

Thanks to its common framework, LINKAGE tool may be used in either a technology pull or a biology push approach. The abstraction and transfer steps are not field related which should make LINKAGE a tool adaptive to any kind of project.

Finally, as the build of such representations, and more broadly of a biomimetic project, demands time and resources, it appears as a fundamental aspect for companies to capitalize on the acquired knowledge. In addition, biologists' system of reward is based on knowledge. Consequently, we support the idea that a biomimetics innovation strategy must be implemented along with a knowledge management strategy. Such strategy is intended to be made available by LINKAGE. Its representations are likely to gather a lot of interconnected information that may be used as a storage format, enlarging a database or an ontology with structured and interrelated information.

The synthesis of a common framework of reference and its implementation through LINKAGE thus aim to decrease cognitive dissonances all along the biomimetic process.

7.2 Contributions to the Encoding and Decoding Processes. This Sec. 7.2 explores LINKAGE targeted contributions on a second noises' source, the encoding and decoding processes (Sec. 2.3.2).

First, the variability of mental models representing the project's objectives, constraints, and the system to design can lead to misunderstandings (psychological noise). As a result, the encoded messages may be irrelevant.

Moreover, because of frameworks' differences, a relevant message can be inadequately encoded or decoded. This aspect does not appear specific to interdisciplinary teams, but the risk of non-compatible mental representations seems higher in such cases.

Through the incorporation of the project's objectives within the states and the formalization of information in a shared framework of reference (constraints, elements to consider, interactions, and functions), LINKAGE aims at supporting a common understanding of the project. The tool should also allow teammates to encode and decode signals through the same overall prism defined by the co-designed LINKAGE representations.

Second, semantic noises were identified as an issue. Where vocabulary has not been considered in this article, LINKAGE contributions on contextualization is here discussed.

The tool should lead the team to represent concepts in interconnected networks. The increase in the number of characterizing interactions may help teammates to correctly interpret concepts, and so to decrease semantic noises. This reasoning may also lead the team to identify understanding errors. Furthermore, the context surrounding potential missing information may be better characterized, leading to the encoding of a clear communication signal to be exchanged with external experts from engineering or biology (vertical biologist).

Finally, the model is designed to act as an interface between fieldspecific representations. As a result, LINKAGE should give teams the ability to encode field-specific message through common representations. The tool may then act as new communication channel.

LINKAGE then targets the reduction of semantic noises through contextualization and the formalization of new communication channels having specific encoding/decoding processes. Section 7.3 presents what LINKAGE's specificities are compared with the other available tools.

7.3 LINKAGE, Why Isn't it Just Another Tool? This last section summarizes in a short table the main aspects differentiating LINKAGE from other biomimetic tools presented in Sec. 2 (Table 5). The key difference of our work lays in its research axis. Through the designing of a common framework of reference for stakeholders coming from different fields, this publication investigates interdisciplinary team's internal communication. Following guidelines involving a series of cognitive shifts, we presented a framework designed for practitioners to find spaces to express themselves. LINKAGE appears as an embodiment of these guidelines, guiding interdisciplinary teams during the biomimetic process.

We truly believe that performing the conceptual shift needed to design tools for biomimetic interdisciplinary teams is crucial for the actual integration of biologists (whatever their actual profile might be) in design teams and during the practice of biomimetics.

These interdisciplinary interactions are the very core and wealth of biomimetics and are requirements for teammates to transcend their fields to form a transdisciplinary whole in the long run.

\section{Perspectives}

As presented in Sec. 1, this study on communication within interdisciplinary biomimetic design teams is composed of two parts. This article presents the theoretical foundation behind the tool, but we are currently working on its practical implementation.

Since there is an inherent difficulty for users to combine different forms of information (image, video, scientific references, description, etc.) on paper, and because it should make dissemination and capitalization much easier, a computerized version of the tool is currently under development. It should also allow 
the automation of some redundant steps to increase the tools ergonomics.

Furthermore, this computerized version will allow us to test the tool's impact at a greater scale and implement feedback loops to keep on improving its ergonomics, design new features and implement the knowledge capitalization through closed or open databases depending on the use.

As previously described, we are also working on the potentialities offered by LINKAGE regarding the identification and the selection of biological models.

On a more general note, our current work focuses on the remaining issues about biologists' integration, which is the ill-defined horizontal biologist profile.

The difficulty here arises because only a few tools and processes are designed to include biologist. Taking such a starting point, it locked the door for biologists, leading engineers themselves to have trouble formulating realistic expectations for biologists. As a result, it appeared necessary to start by focusing on the overall framework adjustment (Why? When? Where? How to include this potential new profile?) before determining and training (How to match design team expectations?) a fitting new profile having a background in a biology and cross-disciplinary skills.

All along this article, we talked about horizontal biologists to ease the reading but the question whether the profile of interest is a biologist per se or another type of profile (engineer, designer, etc.) having followed specific training in biology remains unsolved and will be extensively studied in coming articles.

\section{Conclusion}

This publication dealt with the integration of a new profile having an expertise in biology within biomimetic design teams. This study takes the hypothesis of an already integrated actor and wonders about his/her ability to act in a symbiotic way with the rest of the team. Communication, as a crucial aspect of teamwork and a wellknown issue during pluridisciplinary project, is at the center of our reflection. Anticipating on those challenges to fully benefit from biologists' valuable expertise appears as a requirement to support their proper integration.

Through the literature review, we identified various noises at the origin of communication problems and chose to focus on expression spaces (channel), cognitive dissonance, encoding format, and decoding process, and more generally on the framework of reference leaving aside the issue of field-specific vocabulary.

The research question studied in this article was: "Can we define a common framework of reference to support communication between biologists and engineers in interdisciplinary biomimetic design teams?"

By looking at both design or biological processes and graphic representations, the first contribution of this article is the extraction of various concepts and cognitive shifts that were turned into nine guidelines structuring a framework of reference common for both integrated biologists and classic design team members. Second, through the embodiment of those guidelines (Table 3), LINKAGE, an interdisciplinary tool leading to support the synergic reasoning of the biomimetic design team was designed. Finally, its compatibility with preexisting conceptual frameworks and its targeted contributions are described.

The second part of this study, combining applications, tests' results, and users' feedback, will be soon addressed along with the release of a computerized version of LINKAGE. This openaccess tool will be available to the greatest number possible in the form of a website.

\section{Data Availability Statement}

The authors attest that all data for this study are included in the paper.

\section{References}

[1] Benyus, J. M., 1997, Biomimicry: Innovation Inspired by Nature, Quill, New York.

[2] ISO/TC266, 2015, "Biomimétique-Terminologie, Concepts et Méthodologie."

[3] Keshwani, S., Lenau, T. A., Ahmed-Kristensen, S., and Chakrabarti, A., 2017, "Comparing Novelty of Designs From Biological-Inspiration With Those From Brainstorming," J. Eng. Des., 28(10-12), pp. 654-680.

[4] Ahmed-Kristensen, S., Christensen, B. T., and Lenau, T., 2014, "Naturally Original: Stimulating Creative Design Through Biological Analogies and Random Images," International Design Conference, DESIGN, Dubrovnik, pp. $427-436$.

[5] Yen, J., Helms, M. E., Goel, A. K., Tovey, C., and Weissburg, M., 2014 "Adaptive Evolution of Teaching Practices in Biologically Inspired Design," Biologically Inspired Design, 1st ed., Vol. 1, A. K. Goel, D. A. McAdams, and R. B. Stone, eds., Springer-Verlag London, London, pp. 153-199.

[6] Chirazi, J., Wanieck, K., Fayemi, P. E.,Zollfrank, C., and Jacobs, S., 2019, "What Do We Learn From Good Practices of Biologically Inspired Design in Innovation?," Appl. Sci., 9(4), p. 650.

[7] McCardle, J., Angus, R., and Trott, J., 2019 "Transdisciplinary Design Practices in Education: A Complex Search for Innovation in Nature," International Conference on Engineering and Product Design Education - E\&PDE, Glasgow, UK, Sept. 12-13.

[8] Wanieck, K., Fayemi, P. E., Maranzana, N., Zollfrank, C., and Jacobs, S. R., 2017, "Biomimetics and Its Tools," Bioinspir. Biomimet. Nanobiomater., 6(2), pp. 53-66.

[9] Jacobs, S. R., Nichol, E. C., and Helms, M. E., 2014 "“Where Are We Now and Where Are We Going?' The BioM Innovation Database," ASME J. Mech. Des., 136(11), p. 111101

[10] Bar-Cohen, Y., 2006, "Biomimetics-Using Nature to Inspire Human Innovation," Bioinspir. Biomimet., 1(1), pp. P1-P12.

[11] Vincent, J. F. V., 2009, "Biomimetics-A Review," Proc. Inst. Mech. Eng., Part H, 223(8), pp. 919-939.

[12] Fayemi, P.-E., Wanieck, K., Zollfrank, C., Maranzana, N., and Aoussat, A., 2017, "Biomimetics: Process, Tools and Practice," Bioinspir. Biomimet., 12(1), p. 11002.

[13] Lindemann, U., and Gramann, J., 2004, "Engineering Design Using Biological Principles," International Design Conference, DESIGN, Dubrovnik, pp. 355-360.

[14] Lenau, T., 2009, "Biomimetics as a Design Methodology-Possibilities and Challenges," International Conference on Engineering Design, ICED, Standford, pp. 121-132.

[15] Goel, A. K., Vattam, S., Wiltgen, B., and Helms, M. E., 2014, "InformationProcessing Theories of Biologically Inspired Design," Biologically Inspired Design, 1st ed., Vol. 1, A. K. Goel, D. A. McAdams, and R. B. Stone, eds., Springer Verlag London, London, pp. 127-152.

[16] Weidner, B. V., Nagel, J., and Weber, H. J., 2018, "Facilitation Method for the Translation of Biological Systems to Technical Design Solutions," Int. J. Des. Creat. Innov., 6(3-4), pp. 211-234.

[17] Graeff, E., Maranzana, N., and Aoussat, A., 2019, 'Engineers' and Biologists' Roles During Biomimetic Design Processes, Towards a Methodological Symbiosis," International Conference on Engineering Design - ICED, Delft, The Netherlands, Aug. 5-8, pp. 319-328

[18] Vincent, J. F. V., Bogatyreva, O. A., Bogatyrev, N. R., Bowyer, A., and Pahl, A. K., 2006, "Biomimetics: Its Practice and Theory," J. R. Soc. Interface, 3(9), pp. $471-482$

[19] Ohno, T., 1978, Toyota Production System: Beyond Large-Scale Production, Productivity Press, Cambridge, MA.

[20] Hoagland, M. B., and Dodson, B., 1995, The Way Life Works, Crown, New York.

[21] Vattam, S., and Goel, A., 2013, "Seeking Bioinspiration Online: A Descriptive Account," International Conference on Engineering Design - ICED, Seoul, South Korea, Aug. 19-22, pp. 347-356.

[22] Kruiper, R., Vincent, J. F. V., Abraham, E., Soar, R., Konstas, I., Chen-Burger, J., and Desmulliez, M., 2018, "Towards a Design Process for Computer-Aided Biomimetics," Biomimetics, 3(3), p. 14.

[23] Fayemi, P.-E., Maranzana, N., Aoussat, A., Chekchak, T., and Bersano, G., 2015, "Modeling Biological Systems to Facilitate Their Selection During a Bio-Inspired Design Process," International Conference on Engineering Design - ICED, Milan, Italy, July 27-30, pp. 225-234.

[24] Nagel, J. K. S., Nagel, R. L., Stone, R. B., and McAdams, D. A., 2010, "Function-Based, Biologically Inspired Concept Generation," Artif. Intell. Eng. Des. Anal. Manuf. AIEDAM, 24(4), pp. 521-535.

[25] Sartori, J., Pal, U., and Chakrabarti, A., 2010, "A Methodology for Supporting 'Transfer' in Biomimetic Design," Artif. Intell. Eng. Des. Anal. Manuf. AIEDAM, 24(4), pp. 483-505.

[26] Wynn, D., and Clarkson, J., 2005, "Models of Designing," Design Process Improvement, 1st ed., Vol. 1, J. Clarkson, and C. Eckert, eds., Springer, London, pp. 34-59.

[27] Gericke, K., and Blessing, L., 2011, "Comparisons of Design Methodologies and Process Models Across Disciplines: A Literature Review," International Conference on Engineering Design - ICED, Copenhagen, Denmakrk, Aug. 15-18.

[28] Baumeister, D., Tocke, R., Dwyer, J., Ritter, S., and Benyus, J., 2013, Biomimicry Resource Handbook: A Seed Bank of Knowledge and Best Practices, CreateSpace Independent Publishing Platform, Missoula. 
[29] Freitas Salgueiredo, C., and Hatchuel, A., 2014, "Modeling Biologically Inspired Design With the C-K Design Theory," International Design Conference, DESIGN, Dubrovnik, Croatia, May 19-22.

[30] Snell-Rood, E., 2016, "Interdisciplinarity: Bring Biologists Into Biomimetics," Nature, 529(7586), pp. 277-278.

[31] Graeff, E., Maranzana, N., and Aoussat, A., 2019, "Biomimetics, Where Are the Biologists?," J. Eng. Des., 30(8-9), pp. 289-310.

[32] Helms, M. E., Vattam, S. S., and Goel, A. K., 2009, "Biologically Inspired Design: Process and Products," Des. Stud., 30(5), pp. 606-622.

[33] Shannon, C. E., 1948, “A Mathematical Theory of Communication," Bell Syst. Tech. J., 27(3), pp. 379-423.

[34] Berlo, D. K., 1960, The Process of Communication: An Introduction to Theory and Practice, Holt, Rinehart and Winston, New York.

[35] Schramm, W., 1955, The Process and Effects of Mass Communication, 1st ed., Vol. 1, University of Illinois Press, Urbana, IL, pp. 1-578.

[36] Devito, J. A., 2013, Interpersonal Communication Book, 13th ed., Vol. 1, Pearson, London, pp. 1-432.

[37] Bogatyrev, N. R., and Bogatyreva, O. A., 2015, "TRIZ-Based Algorithm for Biomimetic Design," Procedia Engineering, Vol. 131, D. Cavallucci, G. Cascini, J. Duflou, P. Livotov, and T. Vaneker, eds., Elsevier, New York, pp. 377-387.

[38] Nagel, J., Schmidt, L., and Born, W., 2018, "Establishing Analogy Categories for Bio-Inspired Design," Designs, 2(4), p. 47.

[39] Chown, B., 2017, "The Design Team as a 'System of Systems'," 2017 IEEE International Systems Engineering Symposium (ISSE), IEEE, pp. 1-5.

[40] Cheong, H., Chiu, I., Shu, L. H., Stone, R. B., and McAdams, D. A., 2011 , "Biologically Meaningful Keywords for Functional Terms of the Functional Basis," ASME J. Mech. Des., 133(2), p. 021007.

[41] Nagel, J. K. S., Stone, R. B., and McAdams, D. A., 2011, "An Engineeringto-Biology Thesaurus for Engineering Design," ASME 2010 International Design Engineering Technical Conference \& Computers and Information in Engineering Conference, Montreal, Canada, Aug. 15-18, pp. 117-128.

[42] Biomimicry Institute, 2002, "AskNature-Innovation Inspired by Nature," AskNature, pp. 27-29. https://asknature.org/, Accessed Nov. 23, 2018.

[43] Vincent, J. F. V., 2014, "An Ontology of Biomimetics," Biologically Inspired Design, 1st ed., Vol. 1, A. K. Goel, D. A. McAdams, and R. B. Stone, eds., Springer, London, pp. 269-285.

[44] Vincent, J., and Cavallucci, D., 2018, "Development of an Ontology of Biomimetics Based on Altshuller's Matrix," Automated Invention for Smart Industries. TFC 2018. IFIP Advances in Information and Communication Technology, Vol. 541, D. Cavallucci, R. De Guio, and S. Koziołek, eds., Springer, Cham, pp. 14-25.

[45] Vattam, S., Wiltgen, B., Helms, M. E., Goel, A. K., and Yen, J., 2010, "DANE: Fostering Creativity in and through Biologically Inspired Design," Design Creativity 2010, 1, Vol. 1, T. Taura, and Y. Nagai, eds., Springer, London, pp. $115-122$.

[46] Chakrabarti, A., Sarkar, P., Leelavathamma, B., and Nataraju, B. S., 2005, "A Functional Representation for Aiding Biomimetic and Artificial Inspiration of New Ideas," Artif. Intell. Eng. Des. Anal. Manuf. AIEDAM, 19(2), pp. 113-132.

[47] Maturana, H. R., and Varela, F. J., 1980, Autopoiesis and Cognition: The Realization of the Living, Vol. 42, Springer Netherlands, Dordrecht.

[48] Miller, J. G., 1978, Living Systems, 1st ed., Vol. 1, McGraw-Hill, New York.

[49] Altshuller, G. S., 1984, Creativity as an Exact Science: The Theory of the Solution of Inventive Problems, Gordon and Breach Science Publishers, New York.

[50] Siegel, D. S., Waldman, D. A., Atwater, L. E., and Link, A. N., 2004, "Toward a Model of the Effective Transfer of Scientific Knowledge From Academicians to Practitioners: Qualitative Evidence From the Commercialization of University Technologies," J. Eng. Technol. Manag., 21(1-2), pp. 115-142.

[51] Falkenhainer, B., Forbus, K. D., and Gentner, D., 1989, "The Structure-Mapping Engine: Algorithm and Examples," Artif. Intell., 41(1), pp. 1-63.

[52] Gentner, D., 1983, "Structure-Mapping: A Theoretical Framework for Analogy," Cogn. Sci., 7(2), pp. 155-170.
[53] Helms, M. E., and Goel, A. K., 2014, "The Four-Box Method of Problem Specification and Analogy Evaluation in Biologically Inspired Design," Volume 7: 2nd Biennial International Conference on Dynamics for Design; 26th International Conference on Design Theory and Methodology, Buffalo, NY, Aug. 17-20, ASME, p. V007T07A005.

[54] Hashemi Farzaneh, H., Helms, K., and Lindemann, U., 2015, "Visual Representations as a Bridge for Engineers and Biologists in Bio-Inspired Design Collaborations," Proceedings of the International Conference on Engineering Design - ICED, Milan, Italy, July 27-30, ICED, pp. 215-224.

[55] Mathieu, J. E., Goodwin, G. F., Heffner, T. S., Salas, E., and Cannon-Bowers, J. A., 2000, "The Influence of Shared Mental Models on Team Process and Performance," Psychol. Assoc. Inc, 85(2), pp. 273-283.

[56] Choi, B., and Pak, A., 2006, "Multidisciplinarity, Inter-Disciplinarity and Trans-Disciplinarity in Health Research," Clin. Investig. Med., 29(6), pp. 351364.

[57] Alvargonzález, D., 2011, "Multidisciplinarity, Interdisciplinarity, Transdisciplinarity, and the Sciences," Int. Stud. Philos. Sci., 25(4), pp. 387-403.

[58] Lotrecchiano, G., 2010, "Complexity Leadership in Transdisciplinary (TD) Learning Environments: A Knowledge Feedback Loop,” Int. J. Transdiscipl. Res., 5(1), pp. 29-63.

[59] Merriam-Webster Dictionary, 2020, "Frame of Reference." https://www.merriamwebster.com/dictionary/frame of reference, Accessed Mar. 20, 2020.

[60] Gentner, D., 2002, "Psychology of Mental Models," International Encyclopedia of the Social \& Behavioral Sciences, N. J. Smelser, and P. B. Baltes, eds., Pergamon Press, Oxford, pp. 9683-9687.

[61] Bernard, C., and Wolf, S., 1999, Experimental Medicine, 1st ed., Vol. 1, Routledge, New York, pp. 23-32.

[62] Pahl, G., Beitz, W., Wallace, K., Blessing, L. T. M., and Bauert, F., 1996, Engineering Design: A Systematic Approach, Springer, New York.

[63] De Rosnay, J., 1977, "Le Macroscope. Vers Une Vision Globale (The Macroscope Towards a Comprehensive Vision)," Popul., 32(6), p. 1319.

[64] Fayemi, P. E., Maranzana, N., Aoussat, A., and Bersano, G., 2014, "Bio-Inspired Design Characterisation and Its Links with Problem Solving Tools," International Design Conference, DESIGN, Dubrovnik, Croatia, July 19-22, pp. 173-182.

[65] Simon, H. A., 1969, The Sciences of the Artificial, MIT Press, Cambridge, MA.

[66] Bouchard, C., Camous, R., and Aoussat, A., 2005, "Nature and Role of Intermediate Representations (IR) in the Design Process: Case Studies in Car Design," Int. J. Veh. Des., 38(1), pp. 1-25.

[67] Wainwright, S. A., 1988, "Form and Function in Organisms," Integr. Comp. Biol., 28(2), pp. 671-680.

[68] Forehand, C. J., 2009, Medical Physiology: Principles for Clinical Medicine, 3rd ed., Vol. 1, R. A. Rhades, D. R. Bell, eds., Lippincott Williams \& Wilkins, Philadelphia, pp. 43-43.

[69] Sedgwick Minot, C., 1907, "The Problem of Age, Growth, and Death," The Popular Science Monthly, 71(3), pp. 211

[70] Haefner, J. W., 2005, Modeling Biological Systems:Principles and Applications, 2nd ed., Springer, New York, pp. 1-475.

[71] Waterman, T. H., 1968, "Systems Theory and Biology-View of a Biologist," Systems Theory and Biology, 1st ed., Vol. 1, M. D. Mesarović, ed., Springer, Berlin, Heidelberg, pp. 1-37.

[72] Karsenti, E., 2008, "Self-Organization in Cell Biology: A Brief History," Nat. Rev. Mol. Cell Biol., 9(3), pp. 255-262.

[73] Jacob, F., 1993, The Logic of Life: A History of Heredity, New edition, Princeton University Press, Princeton, pp. 1-362.

[74] Le Moigne, J. L., 1994, La Théorie Du Système Général: Théorie de La Modélisation (General System Theory: Theory of Modelling), Presses universitaires de France, Paris.

[75] Barthlott, W., Schimmel, T., Wiersch, S., Koch, K., Brede, M., Barczewski, M., Walheim, S., Weis, A., Kaltenmaier, A., Leder, A., and Bohn, H. F., 2010, "The Salvinia Paradox: Superhydrophobic Surfaces With Hydrophilic Pins for Air Retention Under Water," Adv. Mater., 22(21), pp. 2325-2328. 